\title{
NOTE
}

\section{Larvae of the sea hare Aplysia californica settle and metamorphose on an assortment of macroalgal species}

\author{
Joseph R. Pawlik*
}

Scripps Institution of Oceanography, University of California, San Diego, La Jolla, California, 92093-0208, USA

\begin{abstract}
Larvae of the sea hare Aplysia californica (Mollusca: Opisthobranchia) spend several weeks feeding in the plankton prior to settlement and metamorphosis. Previous work indicated that metamorphosis was triggered by only one (or at most a few) algal species. However, in the present laboratory study, a mean of $30 \%$ or more of the larvae of this sea hare metamorphosed in response to 10 of 18 species of intertidal macroalgae ( 9 red, 7 brown, 2 green). Metamorphosis was greatest in response to the red algae Rhodymenia californica, Corallina officinalis, Plocamium cartilagineum and Laurencia pacifica. Juveniles of A. californica that had metamorphosed on the last 2 species grazed on them and began to grow, whereas juveniles on the other species tended to crawl off the alga and around the assay dish. Of the 8 algae least preferred, only 1 was red, the remainder brown or green. For larvae of $A$. californica, metamorphosis on a relatively wide spectrum of algal species may be more efficacious than metamorphosis on any one alga, because juvenile sea hares can readily crawl to nearby algal species that they prefer to eat after they have metamorphosed on an alga that is not their preferred food.
\end{abstract}

Most marine invertebrates pass through a planktonic larval stage prior to settlement and metamorphosis, and the recruitment of their larvae is important in structuring benthic marine communities (Keough \& Downes 1982, Keough 1983, Gaines \& Roughgarden 1985). Larval settlement is largely regarded as a response to complex, and often highly specific, environmental stimuli (Burke 1983, Crisp 1984), especially chemical cues (reviewed in Hadfield 1986, Pawlik \& Faulkner 1986). However, few naturally-occurring chemical inducers of larval settlement and metamorphosis have been isolated and identified (Kato et al. 1975, Cuomo 1985, Pawlik 1986).

\footnotetext{
- Present address: Friday Harbor Laboratories, University of Washington, 620 University Road, Friday Harbor, Washington 98250 , USA
}

Marine molluscs of the genus Aplysia are among the most intensively studied animals on earth and have been the subject of research on development, growth and energetics, circadian rhythms, and the neural basis for learning, memory and behavior (reviewed in Kandel 1979, Carefoot 1987). Research interest in one of the best studied sea hares, $A$. californica, from the coast of California, prompted the laboratory cultivation of the planktotrophic larvae of these animals through metamorphosis (Kriegstein et al. 1974). In the field, young recruits of these herbivorous snails were most frequently found eating red algae, primarily of the genus Laurencia (Kupfermann \& Carew 1974). Moreover, several putatively defensive halogenated natural products isolated from adult $A$. californica were found to be derivatives of metabolites of L. pacifica (Stallard \& Faulkner 1974), suggesting some dependence of the molluscs on this alga

Larval settlement of Aplysia californica was reported to be highly substrate-specific, and chemical inducers were believed to be responsible for substrate choice (reviewed in Carefoot 1987). Kriegstein et al. (1974) found that laboratory-reared larvae would settle and metamorphose on Laurencia pacifica, but not on species of Plocamium, Polysiphonia, Daysia, Chondrus or Ulva. Subsequently, Capo et al. (1979) reported that 2 red algae from the New England coast, Neoagardheilla baileyi and Gracilaria sp., would also induce settlement and metamorphosis of $A$. californica. The study described herein was initiated in an effort to isolate and identify compounds from $L$. pacifica that induced metamorphosis of A. californica. It was discovered, however, that metamorphosis of $A$. californica was much less specific than had been previously reported. 
Materials and methods. All larvae used in experiments were the progeny of 2 specimens of Aplysia californica that had been cultured as larvae in the lab, had metamorphosed upon exposure to branchlets of Laurencia pacifica, and had been reared from juveniles to reproductive adults on a diet of Plocamium cartilagineum and $L$. pacifica. Small pieces of egg mass were placed in aerated beakers containing $1 \mu \mathrm{m}$-filtered, natural seawater (hereafter referred to as 'seawater') until hatching occurred. Larvae were then transferred to $2 \mathrm{l}$ Fernbach flasks filled to the neck with seawater containing $40 \mathrm{mg} \mathrm{l}^{-1}$ each of the antibiotics streptomycin sulfate and sodium penicillin G (Sigma Chemical Co., St. Louis, Missouri) and $10^{4}$ cells $\mathrm{ml}^{-1}$ of the green flagellate Pavlova lutheri. Larval entrapment at the air/water interface was prevented by spreading flakes of cetyl alcohol (1-hexadecanol, Sigma) on the water surface. Flasks were kept at $20^{\circ} \mathrm{C}$ in a chamber $35 \mathrm{~cm}$ beneath 2 continuously-illuminated $60 \mathrm{~W}$ fluorescent lights.

Every $4 \mathrm{~d}$, culture vessels were cleaned. Contents of the flask were poured through a series of mesh screens so as to retain the larvae while eliminating larger and smaller particles. The flasks were then scrubbed with hot, fresh water, rinsed in seawater, and reconstituted as before. Cultures were stirred with a jet of $25 \mathrm{ml}$ of seawater once each day. Using these techniques, larvae exhibited growth rates comparable to those observed in other studies (Kriegstein et al. 1974, Paige 1986).

Larvae were competent to metamorphose approximately $35 \mathrm{~d}$ after hatching and were used in assays 40 to $60 \mathrm{~d}$ after hatching. The development of 4 to 6 red spots on the perivisceral membrane of the larvae did not prove to be a reliable indicator of larval maturity, as detailed by Kriegstein (1977), because larvae lacking perivisceral spots frequently underwent normal settlement and metamorphosis. Twenty larvae were transferred to each glass assay dish ( $8 \mathrm{~cm}$ diam., $4 \mathrm{~cm}$ high) containing 60 to $70 \mathrm{ml}$ of seawater coated with flakes of cetyl alcohol. Branchlets of intertidal algae having roughly equivalent surface areas were added to each dish (no alga was added to the control dish). The water surface in each dish was examined under a dissecting microscope, and the larvae trapped in the air/water interface were freed by hitting them with drops of seawater. Dishes were covered with white paper (to decrease light levels and prevent algal branchlets from forming bubbles and floating to the surface) and placed under the same lighting and temperature conditions that had been employed in larval culture. After $2 \mathrm{~d}$, dishes were cleaned in the same manner as larval culture vessels, and the dishes reconstituted as they had been at the start of the assay.

After $4 \mathrm{~d}$, assay dishes, and the algae contained therein, were examined under a dissecting microscope to determine the number of larvae that had undergone metamorphosis. Juveniles had lost their velar cilia and the rudiments of their velar lobes had grown anteriorly to extend beyond the shell when crawling (see Kriegstein 1977, for drawings and details). Unmetamorphosed larvae were distinguished by the presence of velar cilia, whether crawling or not. Larvae and juveniles were removed as they were counted. Metamorphosed larvae were often difficult to locate, particularly on highly branched algae, and data were discarded if less than 15 of 20 larvae or juveniles were recovered per dish.

The intertidal macroalgae used in the assays were collected from Casa Cove and Dike Rock, La Jolla, California, in April and May 1987. Branchlets of algae were added to assay dishes within $24 \mathrm{~h}$ of collection. Only branchlets tree of epiphytes were used in assays and all associated fauna were removed prior to their transfer to assay dishes. Algal identifications were based on Abbott \& Hollenberg (1976). Algae used were: Codium fragile and Ulva sp. (Chlorophyta); Colpomenia sinuosa, Dictyopteris undulata, Enderachne binghamiae, Pachydictyon coriaceum, Pelvetia fastigiata, Sargassum muticum and Zonaria farlowii (Phaeophyta); and Callophyllis violacea, Centroceras clavulatum, Chondria californica, Corallina officinalis, Gigartina canaliculata, Laurencia pacifica, Plocamium cartilagineum, Pterocladia capillacea and Rhodymenia californica (Rhodophyta).

Preliminary experiments were performed in an attempt to characterize the chemical inducers of metamorphosis of Aplysia californica. Branchlets of Plocamium cartilagineum and Laurencia pacifica were separately frozen and freeze-dried, and a portion of the freeze-dried algae was sequentially extracted in distilled organic solvents (hexanes, diethyl ether, ethyl acetate and methanol, in that order). The resulting extracts of each alga were combined and coated onto a disk of filter paper (Whatman, $4 \mathrm{~cm}$ diameter). Disks and extracted algae were placed under a vacuum to remove all traces of solvents. Assays were run as before with living, freeze-dried and freeze-dried and extracted algae, and algal extracts on filter paper Freeze-dried and freeze-dried and extracted algae were first rehydrated in seawater under a vacuum.

All assays were run with 3 replicates and the mean percentage of larval response for each assay determined. Differences in mean percentage metamorphosis were tested with 1 -way analysis of variance (ANOVA) performed on arcsin-transformed data. The Tukey test was applied a posteriori to determine which treatments resulted in different mean larval responses at the 0.05 level of significance (Zar 1984).

Results. Contrary to previous reports (Kriegstein et 
al. 1974, Kriegstein 1977), larvae of Aplysia californica did not settle and metamorphose specifically on Laurencia pacifica (Fig. 1). Although there were significant differences in mean metamorphosis among treatments (ANOVA, $F_{18,38}=4.22, p<0.001$ ), analysis of the differences between means (Turkey test, $\alpha=0.05$ ) revealed no difference between larval response to $L$. pacifica and any of the other algae tested. There was significantly greater metamorphosis in dishes containing one of the 4 species of red algae, Rhodymenia californica, Corallina officinalis, Plocamium cartilagineum or $L$. pacifica, than in control dishes. A mean of $30 \%$ or more larvae metamorphosed in response to 10 of the 18 algae tested, of which 8 species were red algae and 2 species were brown. Of the 8 algae least preferred, only 1 was red, the remainder were brown and green.

Some larvae (3.4\%) metamorphosed in control dishes containing no algae at all. This result was corroborated by the frequent discovery of juvenile sea hares on the walls of culture vessels containing larvae older than $50 \mathrm{~d}$. Larvae in culture vessels would likely

Percent Metamorphosis

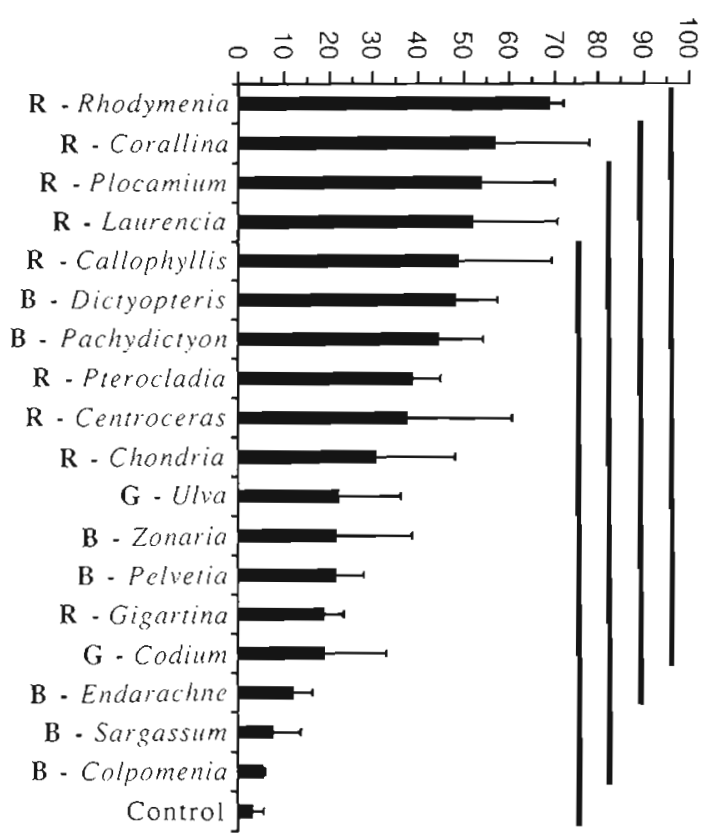

Fig. 1. Aplysia californica. Percentage metamorphosis of larvae in laboratory assay dishes containing branchlets of intertidal macroalgae. Horizontal line extending beyond each histogram indicates 1 standard deviation above the mean $(N=3)$. Vertical bars to the right of the histograms overlap algal species that do not significantly differ in their induction of larval metamorphosis (Tukey test, $\alpha=0.05$ ). The letter preceding each genus name indicates whether the alga is red $(R)$, brown (B) or green (G). Species names of algae are listed in text have come in contact with a film of Pavlova lutheri that colonized the bottom and sides of the culture vessel. Larvae in the control dishes, however, were exposed only to clean glass surfaces in seawater containing no phytoplankton. Therefore, it appears that a small percentage of the larvae of Aplysia californica will metamorphose in response to nothing more than a hard substrate.

In the course of scoring assay dishes, it was noted that juveniles of Aplysia californica in dishes containing Laurencia pacifica and Plocamium cartilagineum were most often found grazing on the algae, but juveniles in dishes containing any of the other algae were most often found crawling on the bottom or sides of the dish. Recently-metamorphosed juveniles that were given only Ulva sp. to eat consumed small amounts of the alga, and showed some growth, but spent most of their time crawling around their container and eventually died. Although juveniles of A. californica seem to require a diet of $L$. pacifica or $P$. cartilagineum, this did not prevent them from initially metamorphosing on other species of algae.

There was no significant difference between mean larval response to branchlets of Plocamium cartilagineum that were living, freeze-dried or freezedried and extracted, or to extracts spread onto filter paper (Fig. 2). There was a significant difference in mean metamorphosis among treatments $\left(\mathrm{F}_{4.10}=4.61\right.$, $p<0.05$ ), but this difference was solely between dishes containing living $P$. cartilagineum and control dishes. Freeze-drying and organic extraction did not remove the capacity of $P$. cartilagineum to induce metamorphosis. Branchlets of Laurencia pacifica that had been freeze-dried, freeze-dried and extracted, and the resultant extracts on filter paper, all proved toxic to a percentage of larvae to which they were exposed (Fig. 2). Surprisingly, the toxic component did not entirely partition into the organic extract, but was equally present in the fully extracted alga.

Discussion. Considerable research on chemical induction of larval settlement and metamorphosis has been carried out on molluscs (reviewed in Morse 1985 , Hadfield 1986). Larvae of the nudibranch Phestilla sibogae metamorphose specifically in response to a water-soluble substance emanating from the tissue or mucus of the coral on which adult animals feed (Hadfield \& Scheuer 1985). Larval metamorphosis of the abalone Haliotis rufescens may be specific on some species of encrusting red algae (Morse \& Morse 1984; however, compare Slattery 1987, Leighton 1988). The naturally-occurring inducers in each of these systems remain to be identified.

The specificity of larval settlement and metamorphosis of aplysiid gastropods has been reviewed previously (Switzer-Dunlap 1978, Carefoot 1987). With the 


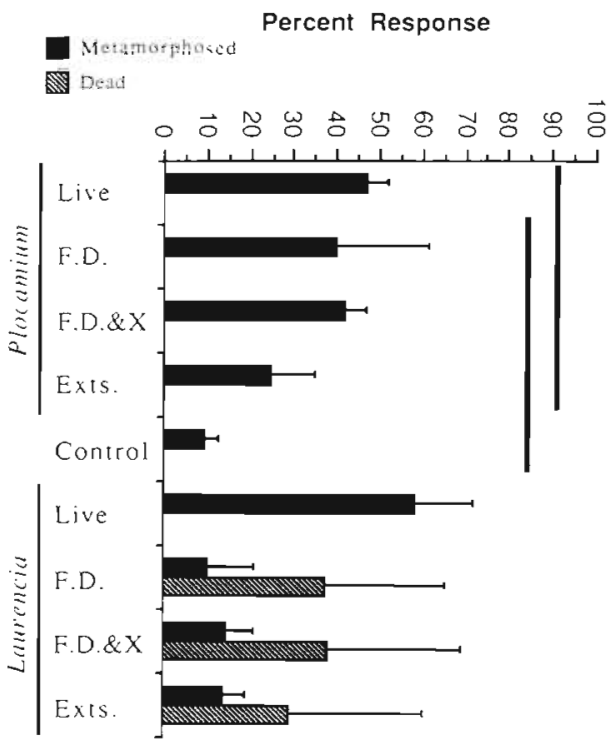

Fig. 2. Aplysia callfornıca. Percentage response of larvae in laboratory assay dishes containing living branchlets of algae (Live), freeze-dried branchlets (F.D.), branchlets that were freeze-dried and extracted with organc solvents (F. D. \& X), and filter paper impregnated with the organic extraxts (Exts.), of the algae Plocamium cartilagineum and Laurencia pacifica. Symbols are the same as in Fig. 1

exception of Aplysia juliana, sea hares of the genus Aplysia metamorphose preferentially on red algae, but in no previous study have these preferences been rigorously assessed. Most frequently, only one or a few species of algae were tested for their ability to induce metamorphosis (e.g. Strenth \& Blankenship 1978, Otsuka et al. 1981). In the case of $A$. californica, the previously reported specificity of larval metamorphosis on Laurencia pacifica was partially inferred from the distribution of young recruits in the field (Kriegstein et al. 1974).

Before a juvenile invertebrate is said to have 'recruited' into its chosen habitat, it must settle, metamorphose, and grow large enough to be counted by an ecologist (Keough \& Downes 1982). Between the time of metamorphosis and recruitment, mortality and (in the case of invertebrates with mobile juveniles) movement can take place. In order to reduce postmetamorphic mortality, many invertebrate larvae appear to exercise considerable selectivity in choosing a substrate on which to settle and metamorphose.

Gregarious settlement is particularly common among species with sessile juveniles and adults (e.g. barnacles, mussels, oysters, tube worms); the presence of adults at the site of settlement is a good indicator that conditions are proper for post-metamorphic survival and growth. In the case of the reef-building tube worm Phragmatopoma lapidosa californica 60 to $90 \%$ of the larvae settle on the tube sand of adult worms, but only about $1 \%$ settle on alternative substrates (Pawlik 1986 1988). Such substrate specificity must have a cost, however. Larvae that 'hold out' in the plankton for the proper settlement cue risk increased mortality resulting from predation and advection to unsuitable habitats.

Unlike sessile species, juveniles of Aplysia californica are mobile immediately after metamorphosis, when they are still $<0.5 \mathrm{~mm}$ in shell length. At the time of recruitment (i.e. detection by the field ecologist), the juveniles have increased in size some 20 -fold and are associated solely with Laurencia pacifica and Plocamium cartilagineum (Kriegstein et al. 1974, Pennings 1988). The observations of the present laboratory study suggest that juvenile A. californica move onto $L$. pacifica and $P$. cartilagineum from other macroalgae after metamorphosis. Larvae of A. californica may decrease the risks associated with 'holding out' for a specific alga by metamorphosing on a variety of macroalgae. Juveniles that have successfully found a macro. algal assemblage are then only required to locate $L$. pacifica and $P$. cartilagineum, both relatively common. For settlement and metamorphosis of A. californica, then, larvae appear to be selective enough to increase the likelihood of juvenile survival, but sufficiently broad in their response so as to minimize larval mortality.

Acknowledgements. I thank T L. Klinger for identifying algae and S. C. Pennings for helpful discussions of this research. This work was supported, in part, by funds provided by the Graduate Department, Scripps Institution of Oceanography, University of California, San Diego.

\section{LITERATURE CITED}

Abbott, I. A., Hollenberg, G. J. (1976). Marine algae of California. Stanford University Press, Stanford, California

Burke, R. D. (1983). The induction of metamorphosis of marine invertebrate Iarvae: stimulus and response. Can. J. Zool. 61: $1701-1719$

Capo, T R., Perritt, S. E., Berg, C. J., Jr (1979). New developments in the mariculture of Aplysia californica. Biol. Bull. mar. biol. Lab., Woods Hole 157: 360

Carefoot, T. H. (1987). Aplysia: its biology and ecology. Oceanogr mar Biol. A. Rev. 25: 176-284

Crisp. D. J. (1984). Overview of research on marine invertebrate larvae, 1940-1980. In: Costlow, J. D., Tipper, R. C. (eds.) Marine biodeterioration: an interdisciplinary study. Naval Institute Press, Annapolis, Maryland, p. 103-126

Cuomo, M C. (1985). Sulphide as a larval settlement cue for Capitella sp. I. Biogeochemistry (Dordrecht) 1 169-181

Gaines, S., Roughgarden, J. (1985). Larval settlement rate: a leading determinant of structure in an ecological community of the marine intertidal zone. Proc. natn. Acad. Sci U.S.A. 82. 3707-3711

Hadfield, M. G. (1986). Settlement and recruitment of marine invertebrates: a perspective and some proposals. Bull. mar. Sci. 39: 418-425

Hadfield, M, G., Scheuer, D. (1985). Evidence for a soluble metamorphic inducer in Phestilla: ecological, chemical and biological data. Bull mar Sci. 37. 556-566 
Kandel, E. R. (1979). Behavioral biology of Aplysia. W H Freeman and Co., San Francisco

Kato, T., Kumanireng, A. S., Ichinose, I., Kitahara, Y, Kakinuma, Y., Nishihira, M. Kato, M. (1975). Active components of Sargassum tortile effecting the settlement of swimming larvae of Coryne uchidar. Experientia 31 433434

Keough, M. J. (1983). Patterns of recrutment of sessile invertebrates in two subtidal habitats. J. exp. mar. Biol. Ecol. 66 : 213-245

Keough, M. J., Downes, B. J. (1982). Recruitment of marine invertebrates: the role of active larval choices and early mortality. Oecologia (Berl.) 54: 348-352

Kriegstein, A. R. (1977). Stages in the post hatching development of Aplysia californica. J. exp. Zool. 199: 275-288

Kriegstein, A. R. Castellucci. V., Kandel, E. R. (1974) Metamorphosis of Aplysia californica in laboratory culture Proc. natn. Acad. Sci. U.S.A. 71: 3654-3658

Kupfermann, I., Carew, T J. (1974). Behavior patterns of Aplysia californica in its natural environment. Behav. Biol. 12: $317-337$

Leighton, D. L. (1988). Abalone mariculture in California and related San Diego-based research. Ann. Report Western Soc. Malacologists 20: 21-25

Morse, A. N. C., Morse, D. E. (1984). Recruitment and metamorphosis of Haliotis larvae induced by molecules uniquely available at the surfaces of crustose red algae. J. exp. mar. Biol. Ecol. 75: 191-215

Morse, D. E. (1985). Neurotransmitter-mimetic inducers of larval settlement and metamorphosis. Bull. mar Sci. 37: $697-706$

Otsuka, C., Oliver, L., Rouger, Y., Tobach, E. (1981). Aplysia punctata added to list of laboratory-cultured Aplysia. Hydrobiologia 83: 239-240

Paige, J. A. (1986). The laboratory culture of two aplysiids, Aplysia brasiliana Rang, 1828, and Bursatella leachii plei (Rang, 1828) (Gastropoda: Opisthobranchia) in artificial seawater Veliger 29: 64-69
Pawlik, J. R. (1986). Chemical induction of larval settlement and metamorphosis in the reef-building tube worm Phragmatopoma californica (Polychaeta: Sabellariidae). Mar. Biol. 91: 59-68

Parvlik, J. R. (1988). Larval settlement and metamorphosis of sibollariid polychaetes, with special reference to Phragmatopoma lapidosa, a reef-building species, and Sabellaria floridensis, a non-gregarious species. Bull. mar Sci. 43: 41-60

Pawlik, J. R., Faulkner, D J. (1986). Specific free fatty acıds induce larval settlement and metamorphosis of the reefbuilding tube worm Phragmatopoma californica (Fewkes). J. exp. mar. Biol. Ecol. 102: 301-310

Pennings, S. C. (1988). Temporal and spatial variation in the recruitment of the sea hare, Aplysia californica, at Santa Catalina Island. In: Recent advances in California island research: Proceedings of the Third California Islands Symposium, in press

Slattery, M. (1987). Settlement and metamorphosis of red abalone (Haliotis rufescens) larvae: a critical examination of mucous, diatoms and $\gamma$-aminobutyric acid (GABA) as inductive substrates. M. A dissertation, San Jose State University, California

Stallard, M. O., Faulkner, D. J. (1974). Chemical constituents of the digestive gland of the sea hare Aplysia californica. I. Importance of diet. Comp. Biochem. Physiol 49B: $25-35$

Strenth, N. E., Blankenship, J. E. (1978). Laboratory culture, metamorphosis and development of Aplysia brasiliana Rang, 1828. Veliger 21: 99-103

Switzer-Dunlap, M. (1978). Larval biology and metamorphosis of aplysiid gastropods. In: Chıa, F. S., Rice, M. E. (eds.) Settlement and metamorphosis of marine invertebrate larvae. Elsevier, New York, p. 197-206

Zar, J. H. (1984). Biostatistical analysis. Second edition. Prentice-Hall, Inc., Englewood Cliffs, New Jersey 